Article

\title{
Gingival Recessions and Periodontal Status after Minimum 2-Year-Retention Post-Non-Extraction Orthodontic Treatment
}

\author{
Livia Nastri $^{1}{ }^{(D)}$, Ludovica Nucci ${ }^{2}$, Domenico Carozza ${ }^{2}$, Stefano Martina ${ }^{3} \mathbb{D}$, Ismene Serino ${ }^{4}$, Letizia Perillo ${ }^{2} \mathbb{D}$, \\ Fabrizia d'Apuzzo ${ }^{2, *(D)}$ and Vincenzo Grassia ${ }^{2}$ (D)
}

check for

updates

Citation: Nastri, L.; Nucci, L.;

Carozza, D.; Martina, S.; Serino, I.; Perillo, L.; d'Apuzzo, F.; Grassia, V. Gingival Recessions and Periodontal Status after Minimum 2-Year-Retention Post-Non-Extraction Orthodontic Treatment. Appl. Sci. 2022, 12, 1641. https://doi.org/10.3390/ app12031641

Academic Editor: Bruno Chrcanovic

Received: 13 January 2022 Accepted: 2 February 2022 Published: 4 February 2022

Publisher's Note: MDPI stays neutral with regard to jurisdictional claims in published maps and institutional affiliations.

Copyright: (c) 2022 by the authors. Licensee MDPI, Basel, Switzerland. This article is an open access article distributed under the terms and conditions of the Creative Commons Attribution (CC BY) license (https:// creativecommons.org/licenses/by/ $4.0 /)$.
1 Periodontal Unit, Multidisciplinary Department of Medical-Surgical and Dental Specialties, University of Campania Luigi Vanvitelli, 80138 Naples, Italy; livia.nastri@unicampania.it

2 Orthodontic Program, Multidisciplinary Department of Medical-Surgical and Dental Specialties, University of Campania Luigi Vanvitelli, 80138 Naples, Italy; ludovica.nucci@unicampania.it (L.N.);

domicarozza1@gmail.com (D.C.); letizia.perillo@unicampania.it (L.P.); grassiavincenzo@libero.it (V.G.)

3 Department of Medicine, Surgery and Dentistry "Scuola Medica Salernitana", University of Salerno, 84081 Baronissi, Italy; smartina@unisa.it

4 Department of Experimental Medicine, University of Campania Luigi Vanvitelli, 80138 Naples, Italy; ismene.serino@unicampania.it

* Correspondence: fabrizia.dapuzzo@unicampania.it; Tel.: +39-081-566-5495 or +39-338-482-0462
Abstract: The objectives of this study were to assess gingival recessions (GR) and periodontal status in patients previously treated with non-extraction orthodontic treatment and retention at a follow-up of a minimum of two years after the end of treatment. Data from patients aged between 16 and 35 years with a previous non-extraction orthodontic treatment and at least 2 years of retention and full records before and after treatment were collected. The casts were digitalized using the 3Shape TRIOS $^{\circledR}$ intraoral scanner and the Viewbox4 software was used for the measurements. The following parameters were scored: inclination of the lower and upper incisors (IMPA and I^SN) and anterior crowding (Little index). The included patients were recalled for a clinical periodontal follow-up examination and the following parameters were evaluated: buccal and lingual GR ( $\mathrm{mm}$ ) of incisors and canines, bleeding of probing score, plaque score, and gingival phenotype. The digital cast analysis showed a mean Little index of 7.78 (SD 5.83) and 1.39 (SD 0.79), respectively, before and after treatment. The initial and final cephalometric analyses showed an I^SN of $103.53^{\circ}$ and $105.78^{\circ}$ (SD 7.21) and IMPA of $91.3^{\circ}$ and $95.1^{\circ}$, respectively. At the follow-up periodontal visits, the patients showed an overall low oral hygiene with bleeding at probing in $66.6 \%$ and plaque in the anterior area in $76.2 \%$ of patients. From the total examined 240 teeth of the frontal sextants, three patients had GR (from 1 to $6.5 \mathrm{~mm}$ ): in the upper arch two at canines and one at central incisor, whereas in the lower arch two at central and one at lateral incisors. The gingival phenotype was thick in $55 \%$ of cases. The lingual-to-lingual retainers at follow-up were present in $61.9 \%$ of patients. A slight increased risk for buccal GR development was found only in correlation with the presence of fixed retainer and thin gingival phenotype mainly in patients with gingivitis. Thus, non-extraction orthodontic treatment performed with controlled forces and biomechanics seems to not affect the development of GR or the periodontal health after retention.

Keywords: gingival recessions; periodontal status; orthodontic treatment; retention; digital casts

\section{Introduction}

Gingival recession (GR) is defined as the apical shift of the gingival margin with respect to the cementoenamel junction (CEJ) [1]; it is associated with attachment loss and exposure of the root surface to the oral environment [2-4]. GR may cause pain, increased tooth sensitivity, compromised aesthetics, and the onset of carious/noncarious cervical lesions (NCCL). Romandini et al. [5] have reported that over $90 \%$ of the adult population in the United States have mid-buccal-gingival recessions whose $70 \%$ is in the aesthetic zone. 
In a subpopulation of subjects from 30 to 39 years of age, the prevalence of GR was assessed as $37.8 \%$ mainly on the buccal sites of the teeth [6]. Several predisposing risk factors have been suggested, such as periodontal phenotype, tooth type and position in the dental arch, amount of attached gingiva, and lack of alveolar buccal bone as well as age, gender, and ethnicity [7-13]. In particular, a thin gingival phenotype was described as a risk factor for inflammation-related GR in the presence of tooth-brushing trauma $[14,15]$ and poor oral hygiene with plaque accumulation [16].

Other studies have also reported that the application of orthodontic forces in specific direction of tooth movements could increase the development or progression of GR during treatment or later in the retention phase [16-19]. According to a recent consensus report on the classification of periodontal and peri-implant diseases and conditions [20], soft tissue alteration can be associated with the buccal-lingual thickness of the gingiva and to the application of orthodontic forces moving teeth out of the alveolar envelope with a localized bony dehiscence and fenestrations [21-23]. A higher prevalence or severity of GR both during and after orthodontic treatment was specifically detected after excessive mandibular incisor proclination [24-27].

Conversely, other authors did not find significant differences in prevalence or severity of GR in orthodontically treated patients compared to a matched non-treated sample [28-32], but other factors such as adulthood and the amount of keratinized gingiva were considered relevant in the onset of GR despite the orthodontic technique applied [33]. Thus, the available literature on this topic is still highly debated and three systematic reviews have summarized the main outcomes $[16,19,24]$. Joss Vassalli et al. [16] confirmed that an excessive incisor movement out of the bone alveolar process could be associated with a higher tendency for developing GR and more buccally proclined teeth had a higher severity of it. However, the same authors commented that the clinical significance of this GR amount may be questionable. Tepedino et al. [34] included only two studies after the qualitative analysis and reported that the effects of orthodontic treatment on the development of GR were not statistically or clinically significant. Therefore, these findings demonstrated weak evidence due to short-term follow up and a significant number of confounding variables without control of the heterogeneity in outcome assessment among the studies, not allowing an adequate meta-analysis. A more recent systematic review of Bin Bahar et al. [19], including three papers with a quantitative analysis on two of them, concluded that an increased risk for GR development on the anterior teeth could be encountered in orthodontically treated compared to untreated individuals with normal occlusion, especially during retention, although the amount of GR did not significantly differ in the whole sample. In conclusion, this topic is highly debated and evidence-based data are still not available on gingival status in orthodontic patients after the retention phase compared to treatment outcomes after non-extraction treatment with fixed appliances.

Thus, the aim of this study was to assess GR and periodontal status in a group of patients previously treated with non-extraction orthodontic treatments and retention with a follow up of minimum two years after the end of active treatment.

\section{Materials and Methods}

The research protocol of this observational study was approved by the Ethics Committee of the University of Campania Luigi Vanvitelli (Prot. $\mathrm{n}^{\circ} 18 / 2018$ ) and a signed informed consent for the use of personal data was available. Data recruitment started in March 2020 and the sample included patients who had consecutively completed their orthodontic treatment between October 2012 and February 2018 at the Orthodontic Program of the University of Campania Luigi Vanvitelli, Naples (Italy). The inclusion criteria were an age between 17 and 35 years; a two-phase non-extraction orthodontic treatment (except for the third molars) with fixed appliances completed at least two years before data collection; the presence of all six dental elements of the frontal upper and lower sextant; and initial and final orthodontic records (lateral cephalometrics, intra/oral photographs, and dental casts of good quality) (Figure 1). The exclusion criteria were systemic pathologies or intake of 
drugs affecting the periodontal status; periodontitis and/or gingival recessions before the beginning of the orthodontic treatment; and the presence of labial or lingual piercings.

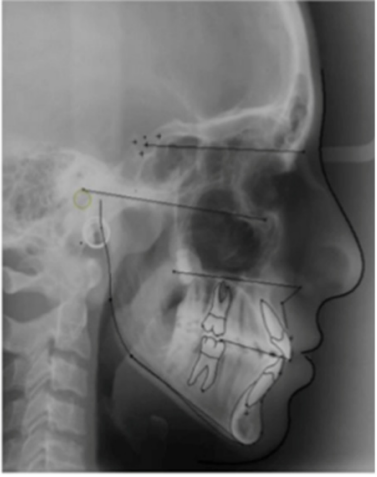

(a)
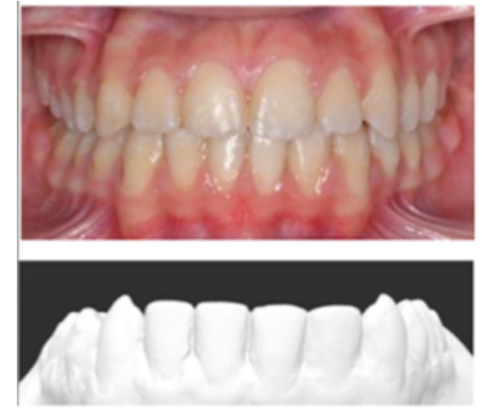

(b)

Figure 1. Post-orthodontic treatment records: cephalometrics (a), photographs, and dental casts (b).

The orthodontic treatment performed in all cases involved in this study included maxillary expander and/or transpalatal arch in the upper and lip bumper in the lower arch during mixed dentition followed by multibracket fixed appliances (MBT prescription) and retention at the end of treatment.

The dental casts were digitalized using the TRIOS ${ }^{\circledR}$ 3Shape intraoral scanner. The Viewbox 4 software (dHal Software, Kifissia, Greece) was used for the measurements on digital models and cephalograms by the same trained operator and the following values were evaluated:

- Anterior crowding through the Little's irregularity index, defined as the sum of displacement of the anatomic contact points of the mandibular anterior teeth [35];

- Inclination of the lower incisors to the mandibular plane (IMPA) and of the upper incisors to the sellar plane (I^SN).

The gingival phenotype was clinically evaluated on the general appearance of the gingiva around the tooth and probing the sulcus: the gingival phenotype was considered thin if the gingiva were delicate, friable, and almost translucent and the periodontal probe were visible through the gingival tissue, whereas it was considered thick if the gingiva were dense and fibrotic in appearance and the probe were not visible [36].

At the clinical recall appointment, a questionnaire on general health and oral hygiene habits (type and frequency of toothbrushing, interdental cleaning, oral washes use) was delivered to each included patient.

A periodontist evaluated the periodontal status and assessed the following parameters:

- Gingival recession, measured in $\mathrm{mm}$ as the distance between the CEJ and coronal margin of the free gingiva, approximated to the nearest $0.5 \mathrm{~mm}$, both on the buccal and lingual surfaces of teeth in the II and V sextants;

- $\quad$ Probing pocket depth (PPD), measured with the Williams-Goldman periodontal probe as the distance from the free gingival margin to the bottom of the sulcus/pocket and approximated to the nearest millimeter at 6 points for each tooth in the II and V sextants;

- Gingival inflammation, evaluated with the Bleeding On Probing (BOP) score according to Ainamo and Bay [37];

- $\quad$ Presence of plaque, evaluated with the Plaque Control record (O'Leary) [38] for the II and V sextants.

If calculus or plaque were present on the tooth surfaces, it was removed before measuring the gingival recessions. The presence and type of orthodontic retention and the evaluation of its integrity were checked during the same appointment by an orthodontist. 


\section{Statistical Analysis}

On the data collected, a descriptive statistical analysis was performed with calculation of the mean and standard deviation. The odds ratio (OR) was used as the risk ratio of association between an exposure and an outcome and represents the odds that an outcome will occur given a particular exposure, compared to the odds of the outcome occurring in the absence of that exposure. Data analysis was performed using the SSPS software. The significance was set at a $p$ value $<0.05$.

\section{Results}

Sixty-three patients met the inclusion criteria and were recalled for follow-up periodontal and orthodontic examinations. Out of these, 22 patients did not respond, or their telephone number was not active while 10 were transferred out of the country and refused to come. These patients were examined at the Orthodontic and Periodontal Programs of the University of Campania Luigi Vanvitelli. They were first interviewed about their current general anamnesis (diabetes, hypertension, endocrine diseases, disvitaminosis, dysmetabolism, heart diseases, kidney diseases, state of nutrition, pregnancy, allergy, ongoing pharmacological therapies), and the presence of all anterior upper and lower dental elements was evaluated. After these follow-up analyses, further 11 patients were excluded.

Thus, a final sample of 20 subjects ( 9 males and 11 female) ranged between 17.1 and 31.10 years (mean age $11.9 \pm 3.7$ years) proceeded with complete periodontal clinical examination. Of these patients, orthodontic and clinical records (dental casts, lateral radiographs and clinical charts) before (T0) and at the end of the active orthodontic fixed treatment (T1) were examined (Table 1).

Table 1. Sample sizes and ages (y), at T0 (the start of orthodontic treatment), T1 (the end of orthodontic treatment), and T2 (follow-up) for the overall sample and subgroups.

\begin{tabular}{ccccccccccc}
\hline Group & Subgroup & $\mathbf{n}$ & \multicolumn{2}{c}{ T0 } & \multicolumn{2}{c}{ T1 } & \multicolumn{2}{c}{ Mean tx Time } & T2 \\
\hline & & & Mean & SD & Mean & SD & Mean & SD & Mean & SD \\
\hline Overall & & 20 & 11.9 & 3.7 & 16.2 & 3.1 & 4.4 & 1.8 & 21.0 & 3.2 \\
\hline Sex & Male & 9 & 10.8 & 1.6 & 15.4 & 1.8 & & 20.8 & 1.9 \\
\hline & Female & 11 & 12.9 & 4.6 & 17.0 & 3.8 & & 21.1 & 3.9 \\
\hline
\end{tabular}

The recruited patients started with the following Angle dental class of malocclusion: 7 patients with Class I, 11 patients with Class II (of which 2 with Class II, division 2), 2 patients with Class III and they were orthodontically treated without tooth extraction (except third molars) with a first phase including maxillary expander and/or transpalatal arch followed by fixed multibrackets appliances in permanent dentition all achieving a Class I. The average treatment duration was of 4.4 years (SD 1.8) (Table 1).

The digital cast analysis before (T0) and at the end (T1) of the orthodontic treatment reported a mean Little's index of 6.83 (SD 3.41) and 1.79 (SD 1.49), respectively (Table 2).

Table 2. Digital cast and cephalometric analysis before (T0) and at the end (T1) of the orthodontic treatment.

\begin{tabular}{|c|c|c|c|c|c|c|c|}
\hline & \multicolumn{2}{|c|}{ T0 } & \multicolumn{2}{|c|}{ T1 } & \multicolumn{2}{|c|}{$\Delta \mathrm{T} 1-\mathrm{T} 0$} & \multirow[t]{2}{*}{$p$} \\
\hline & Mean & SD & Mean & SD & Mean & SD & \\
\hline $\begin{array}{l}\text { Little index } \\
(\mathrm{mm})\end{array}$ & 6.83 & 3.41 & 1.79 & 1.49 & 5.04 & 3.44 & 0.001 * \\
\hline $\mathbf{I}^{\wedge} \mathrm{SN}\left({ }^{\circ}\right)$ & 103.50 & 7.11 & 106.20 & 8.07 & 2.70 & 11.37 & 0.268 \\
\hline IMPA $\left(^{\circ}\right)$ & 91.4 & 7.4 & 95.1 & 10.3 & 3.625 & 8.13 & 0.206 \\
\hline
\end{tabular}


The relationship between Little's index at T0 and the GR development was not present (Table 3). The initial and final cephalometric analyses showed an I^SN angle of $103.50^{\circ}$ (SD 7.11) and $106.20^{\circ}$ (SD 8.07), and an IMPA of $91.4^{\circ}$ (SD 7.4) and 95.1 ${ }^{\circ}$ (SD 10.3), respectively (Table 2). No correlation was shown between incisors inclination and GR (Table 3).

Table 3. Little irregularity index and GR.

\begin{tabular}{ccccccccc}
\hline & GR & & & GR & & GR \\
\hline $\begin{array}{c}\text { Little Index } \\
(\mathbf{m m}) \text { from 1-3 }\end{array}$ & Yes & No & from 3-6 & Yes & No & from 6-9 & Yes & No \\
\hline exposed & 1 & 5 & 1 & 8 & 7 \\
\hline non-exposed & 2 & 12 & 2 & 9 & 10 \\
\hline & OR: 1.201 & & OR: $\mathbf{0 . 4 4 4}$ & & OR: $\mathbf{0 . 7 1 4}$ \\
\hline
\end{tabular}

About the periodontal follow-up recall, from the 240 teeth of the frontal sextants (II and V sextant) examined, 6 teeth had GR (ranging from 1 to $6.5 \mathrm{~mm}$ ), found in three patients. A total of three of these were present in the upper arch and three in the lower arch. In the upper arch two GR were located on the canines, one was on a central incisor, while in the lower arch, all recessions were present on incisors (one central and one lateral).

Only $2.5 \%$ of the total teeth showed buccal GR, and significant results were detected with the odds ratio calculation. From the periodontal point of view, at the beginning of the orthodontic treatment, patients of our sample had a slight prevalence of thick gingival phenotype $\left(n^{\circ} 11\right)$ compared to thin phenotype $\left(n^{\circ} 9\right)$. An odds ratio of 2.857 for the thin phenotype was reported in association to buccal GR, indicating a tendency to be a risk factor. The lingual-to-lingual lower retainers at follow-up were present in the $61.9 \%$ of patients while the others wore removable appliances. A good association was shown between fixed retainers and GR development with an odds ratio of 2,857 (Table 4).

Table 4. Incisor inclinations, gingival phenotype, fixed retainer and GR.

\begin{tabular}{|c|c|c|c|c|c|c|c|c|c|c|c|}
\hline \multicolumn{3}{|c|}{ GR } & \multicolumn{3}{|c|}{ GR } & \multicolumn{4}{|c|}{ GR } & \multicolumn{2}{|c|}{ GR } \\
\hline $\begin{array}{c}\mathrm{I}^{\wedge} \mathrm{SN} \\
>102^{\circ}\end{array}$ & Yes & No & $\begin{array}{l}\text { IMPA } \\
>95^{\circ}\end{array}$ & Yes & No & $\begin{array}{l}\text { Gingival } \\
\text { Phenotype }\end{array}$ & Yes & No & $\begin{array}{c}\text { Fixed } \\
\text { Retainer }\end{array}$ & Yes & No \\
\hline exposed & 2 & 10 & & 1 & 6 & thin & 2 & 7 & present & 2 & 7 \\
\hline $\begin{array}{c}\text { non- } \\
\text { exposed }\end{array}$ & 1 & 7 & & 2 & 11 & thick & 1 & 10 & absent & 1 & 10 \\
\hline & 0.3 & & & R: 0.9 & & & & & & R: 2.8 & \\
\hline
\end{tabular}

Most patients reported brushing twice a day with a manual toothbrush, without the use of dental floss. The use of a reduced brushing frequency (no more than 2 times per day) associated with the lack of cleansing of the interdental spaces may be partly responsible for the observation of increased plaque and bleeding (Table 5). The periodontal biometric parameters did not result in any correlation with GR, neither if analyzed on a patient basis, nor if analyzed on an arch basis or single site. Thus, there was no clear correlation between GR and brushing type and frequency (Table 5).

Table 5. Anamnestic data at follow-up.

\begin{tabular}{cccccccccc}
\hline \multicolumn{2}{c}{$\begin{array}{c}\text { Gingival } \\
\text { Phenotype }\end{array}$} & \multicolumn{2}{c}{$\begin{array}{c}\text { Brushing } \\
\text { Frequency }\end{array}$} & \multicolumn{2}{c}{ Interdental Cleaning } & \multicolumn{2}{c}{ Mouthwash } \\
\hline Thick & Thin & 2/Day & 3/Day & No & Floss & Brush & Occasionally & 2/Day & No \\
\hline 11 & 9 & 15 & 5 & 16 & 2 & 1 & 6 & 4 & 10 \\
\hline
\end{tabular}


At the time of observation for the present study, the periodontal conditions were characterized by the presence of a mean plaque index in sextant II of $20.69 \%$ (SD 31.74\%) and a mean plaque index in sextant $\mathrm{V}$ of $45.42 \%$ (SD 37.88\%). Only 6 of 20 patients had an overall plaque index $<20 \%$. Bleeding on probing was $19.17 \%$ (SD $16.37 \%$ ) in sextant II and $40.28 \%$ (SD 25.18\%) in sextant V, with a similar trend, as expected, with respect to the presence of bacterial plaque. Only five patients had $<20 \%$ bleeding in both sextants analyzed. The mean probing depth for sextant V was 2.08 (SD 0.38), while the corresponding value for sextant II was 2.04 (SD 0.41) (Table 6). Only one of the patients had pathological probing depths $>3 \mathrm{~mm}$ in almost all of the sites of the two sextants analyzed.

Table 6. Periodontal parameters at follow-up.

\begin{tabular}{lcccccc}
\hline & \multicolumn{2}{c}{ Upper Arch } & \multicolumn{2}{c}{ Lower Arch } & \multicolumn{2}{c}{ Full Arch } \\
\cline { 2 - 7 } & Mean & SD & Mean & SD & Mean & SD \\
\hline PPD (mm) & 2.04 & 0.41 & 2.08 & 0.38 & 2.06 & 0.39 \\
\hline BOP (\%) & $19.17 \%$ & $16.37 \%$ & $40.28 \%$ & $25.18 \%$ & $29.72 \%$ & $23.53 \%$ \\
\hline plaque presence (\%) & $20.69 \%$ & $31.74 \%$ & $45.42 \%$ & $37.88 \%$ & $33.06 \%$ & $36.69 \%$ \\
\hline
\end{tabular}

\section{Discussion}

Orthodontic treatment is frequently an elective procedure performed mostly for aesthetic reasons. GR and periodontal diseases may compromise the smile esthetics and general oral health. According to the literature, the prevalence in the general population of GR, mainly buccal, is high tending to increase with age, and sites with recessions were susceptible for additional apical displacement and loss of periodontal support [39]. The aim of this investigation was to recruit only patients without any recession at the start of the orthodontic treatment in order to identify the role of orthodontic treatment in GR occurrence at minimum 2-yr of follow-up. The outcomes of our study showed a very low prevalence of GR compared to the epidemiologic value in the general population at the same age. However, our sample, collected with strict exclusion criteria, showed a prevalence of GR in only $2.5 \%$ of teeth included in our post-retention clinical examination. This was in accordance with the prevalence and distribution found in a cross-sectional and longitudinal study showing a very low occurrence of GR after a follow-up of 12 years of observation in non-treated patients who did not show recessions at baseline [39]. Gebistorf et al. [30] also evaluated recessions after the retention phase in a population of 88 subjects. However, the prevalence of recessions at baseline was $55 \%$, thus justifying the value of $98.9 \%$ at post-retention examination. GR has many confounding predisposing and etiological factors. Orthodontic treatment is one of the more debated iatrogenic factors that have been implicated in its occurrence. According to Sawan et al. [33], non-extraction treatment is related to an increase in risk, with the intercanine width as a negative predictor of gingival recessions. In this study inclination of the incisors was not statistically significant to GR. This in accordance with Morris et al. [31] who found no correlation with incisor proclination (IMPA $>95^{\circ}$ ) in a post-retention population. In our study we did not find any correlation between GR and final IMPA value, even when this value was higher than $95^{\circ}$, nor with the change of inclination. The change of inclination has been claimed as a factor responsible for the occurrence of GR. According to Pernet et al. [26] patients with buccal or lingual recessions presented a mean incisor inclination change of $3^{\circ}$ (range: $-9^{\circ}$ to $23^{\circ}$ ); however, the authors found that among the patients with a more than $10^{\circ}$ inclination change, 12 out of 16 had no recessions. Comparing the prevalence observed in our study, the outcome is similar to Renkema et al. [27] looking at their 2 years of observation. In their study GR increased after 5 years of treatment, but this difference can be confounded by the increase in age of the sample. Although the prevalence of recessions in our study is lower, this could be due to a shorter observation time in our investigation.

According to Vasconcelos et al. [28], incisor retroclination was more correlated to GR than proclination of lower incisors, even if the buccal positioning of central incisors 
are indicated as a major risk factor for its development. Their results indicated a low prevalence of GR after orthodontic treatment, in accordance with our observation, but did not indicate gingival phenotype as a risk factor as well as gingival inflammation, that was found in $29.72 \pm 23.53 \%$ of the examined teeth without correlation to GR. Visible plaque and calculus were a frequent observation (33.06 $\pm 36.03 \%)$. Pandis et al. [40] argue that the presence of a fixed retainer increased the calculus, which possibly contributed to the increase in the number of lingual recessions. However, the presence of the bonded retainer was not correlated with gingivitis or with recessions, all of them found labially. Our findings do not confirm a correlation between bonded retainer and gingivitis or recessions. The overall adherence to oral hygiene effective measures of interdental cleaning was low in our sample, and this can justify the observed high level of plaque and gingivitis. GR may occur as a consequence of alveolar dehiscence, and it seems crucial to apply light forces on multiple teeth rather than to a single tooth [41]. Moreover, discrepancies such as the low prevalence of GR in our study can also be explained by differences in age at assessment, methods of evaluation, or various behavioral influences (hygiene, smoking, and professional periodontal treatment) compared to previous evaluations [5]. The odds ratio was used in this study to approximate the risk ratio because the prevalence of the GR was low, and it an association was detected with the presence of lower fixed retainer and thin phenotype, confirming previous findings [16].

The limitations of this study are the small sample size and the retrospective nature of clinical records before and at the end of the orthodontic treatment, thus the outcomes do not allow definitive statements. Further studies, including a longer follow-up of patients with the similar dentoskeletal characteristics and further prospective assessment of gingival crevicular fluid in patients during and after orthodontic treatment using new and reliable techniques [42], may help to investigate the reasons for GR occurrence in adults and orthodontic population.

\section{Conclusions}

Based on the findings and within the limitations of this study, a non-extraction orthodontic treatment seems to not affect either the development of buccal or lingual recessions or the periodontal status after at least two years of retention post-orthodontics. A slight increased risk for buccal GR development was found only in correlation with the presence of fixed retainer and thin gingival phenotype mainly in patients with gingivitis. Thus, periodical periodontal follow-up appointments after orthodontic treatment are needed to motivate subjects in maintaining a better oral hygiene in the adulthood.

Author Contributions: Conceptualization, L.P. and L.N. (Livia Nastri); methodology, F.d., I.S. and V.G.; data curation, L.N. (Livia Nastri) and L.N. (Ludovica Nucci); writing—original draft preparation, L.N. (Ludovica Nucci) and F.d.; writing-review and editing, S.M. and D.C.; supervision, L.P. and V.G. All authors have read and agreed to the published version of the manuscript.

Funding: This research received no external funding.

Institutional Review Board Statement: The study was conducted in accordance with the Declaration of Helsinki and approved by the Institutional Review Board of the University of Campania Luigi Vanvitelli (protocol code $\mathrm{n}^{\circ} 18 / 2018$ ).

Informed Consent Statement: Informed consent was obtained from all subjects involved in the study.

Data Availability Statement: The data presented in this study are available on request from the corresponding author. The data are not publicly available due to privacy restrictions.

Conflicts of Interest: The authors declare no conflict of interest.

\section{Abbreviations}


GR gingival recession

CEJ cemento-enamel junction

NCCL noncarious cervical lesions

IMPA inclination of the lower incisors to the mandibular plane

I^SN upper incisors to the sellar plane

PPD probing pocket depth

BOP bleeding on probing

\section{References}

1. Pini Prato, G. Mucogingival Deformities. Ann. Periodontol. 1999, 4, 98-101. [CrossRef]

2. Cortellini, P.; Bissada, N.F. Mucogingival Conditions in the Natural Dentition: Narrative Review, Case Definitions, and Diagnostic Considerations. J. Clin. Periodontol. 2018, 45 (Suppl. 2), S190-S198. [CrossRef] [PubMed]

3. Renkema, A.M.; Fudalej, P.S.; Renkema, A.A.P.; Abbas, F.; Bronkhorst, E.; Katsaros, C. Gingival Labial Recessions in Orthodontically Treated and Untreated Individuals: A Case-Control Study. J. Clin. Periodontol. 2013, 40, 631-637. [CrossRef] [PubMed]

4. Zucchelli, G.; Mounssif, I. Periodontal Plastic Surgery. Periodontol. 2000 2015, 68, 333-368. [CrossRef] [PubMed]

5. Romandini, M.; Soldini, M.C.; Montero, E.; Sanz, M. Epidemiology of Mid-Buccal Gingival Recessions in NHANES According to the 2018 World Workshop Classification System. J. Clin. Periodontol. 2020, 47, 1180-1190. [CrossRef]

6. Albandar, J.M.; Kingman, A. Gingival Recession, Gingival Bleeding, and Dental Calculus in Adults 30 Years of Age and Older in the United States, 1988-1994. J. Periodontol. 1999, 70, 30-43. [CrossRef]

7. Hudecki, A.; Kiryczyński, G.; Łos, M.J. Biomaterials, Definition, Overview. In Stem Cells and Biomaterials for Regenerative Medicine; Łos, M.J., Hudecki, A., Wiecheć, E., Eds.; Elsevier: Amsterdam, The Netherlands, 2019.

8. Holtfreter, B.; Schwahn, C.; Biffar, R.; Kocher, T. Epidemiology of Periodontal Diseases in the Study of Health in Pomerania. J. Clin. Periodontol. 2009, 36, 114-123. [CrossRef]

9. Löe, H.; Anerud, A.; Boysen, H. The Natural History of Periodontal Disease in Man: Prevalence, Severity, and Extent of Gingival Recession. J. Periodontol. 1992, 63, 489-495. [CrossRef]

10. Rios, F.S.; Costa, R.S.A.; Moura, M.S.; Jardim, J.J.; Maltz, M.; Haas, A.N. Estimates and Multivariable Risk Assessment of Gingival Recession in the Population of Adults from Porto Alegre, Brazil. J. Clin. Periodontol. 2014, 41, 1098-1107. [CrossRef]

11. Sarfati, A.; Bourgeois, D.; Katsahian, S.; Mora, F.; Bouchard, P. Risk Assessment for Buccal Gingival Recession Defects in an Adult Population. J. Periodontol. 2010, 81, 1419-1425. [CrossRef]

12. Susin, C.; Haas, A.N.; Oppermann, R.V.; Haugejorden, O.; Albandar, J.M. Gingival Recession: Epidemiology and Risk Indicators in a Representative Urban Brazilian Population. J. Periodontol. 2004, 75, 1377-1386. [CrossRef]

13. Zucchelli, G.; Mounssif, I.; Marzadori, M.; Mazzotti, C.; Felice, P.; Stefanini, M. Connective Tissue Graft Wall Technique and Enamel Matrix Derivative for the Treatment of Infrabony Defects: Case Reports. Int. J. Periodontics Restor. Dent. $2017,37,673-681$. [CrossRef] [PubMed]

14. Agudio, G.; Cortellini, P.; Buti, J.; Pini Prato, G. Periodontal conditions of sites treated with gingival augmentation surgery compared with untreated contralateral homologous sites: An 18- to 35-year long-term study. J. Periodontol. 2016, 87, 1371-1378. [CrossRef] [PubMed]

15. Chambrone, L.; Tatakis, D.N. Long-Term Outcomes of Untreated Buccal Gingival Recessions: A Systematic Review and MetaAnalysis. J. Periodontol. 2016, 87, 796-808. [CrossRef] [PubMed]

16. Joss-Vassalli, I.; Grebenstein, C.; Topouzelis, N.; Sculean, A.; Katsaros, C. Orthodontic Therapy and Gingival Recession: A Systematic Review. Orthod. Craniofacial. Res. 2010, 13, 127-141. [CrossRef]

17. Bollen, A.M.; Cunha-Cruz, J.; Bakko, D.W.; Huang, G.J.; Hujoel, P.P. The Effects of Orthodontic Therapy on Periodontal Health: A Systematic Review of Controlled Evidence. J. Am. Dent. Assoc. 2008, 139, 413-422. [CrossRef]

18. Kim, D.M.; Neiva, R. Periodontal Soft Tissue Non-Root Coverage Procedures: A Systematic Review from the AAP Regeneration Workshop. J. Periodontol. 2015, 86, S56-S72. [CrossRef] [PubMed]

19. Bin Bahar, B.S.K.; Alkhalidy, S.R.; Kaklamanos, E.G.; Athanasiou, A.E. Do Orthodontic Patients Develop More Gingival Recession in Anterior Teeth Compared to Untreated Individuals? A Systematic Review of Controlled Studies. Int. Orthod. 2020, 18, 1-9. [CrossRef] [PubMed]

20. Jepsen, S.; Caton, J.G.; Albandar, J.M.; Bissada, N.F.; Bouchard, P.; Cortellini, P.; Demirel, K.; de Sanctis, M.; Ercoli, C.; Fan, J.; et al. Periodontal Manifestations of Systemic Diseases and Developmental and Acquired Conditions: Consensus Report of Workgroup 3 of the 2017 World Workshop on the Classification of Periodontal and Peri-Implant Diseases and Conditions. J. Clin. Periodontol. 2018, 45, S219-S229. [CrossRef] [PubMed]

21. Slutzkey, S.; Levin, L. Gingival Recession in Young Adults: Occurrence, Severity, and Relationship to Past Orthodontic Treatment and Oral Piercing. Am. J. Orthod. Dentofac. Orthop. 2008, 134, 652-656. [CrossRef]

22. Bechara Andere, N.M.R.; dos Santos, N.C.C.; Araujo, C.F.; Mathias, I.F.; Rossato, A.; de Marco, A.C.; Santamaria, M.; Jardini, M.A.N.; Santamaria, M.P. Evaluation of the Local Effect of Nonsurgical Periodontal Treatment with and without Systemic Antibiotic and Photodynamic Therapy in Generalized Aggressive Periodontitis. A Randomized Clinical Trial. Photodiagnosis Photodyn Ther. 2018, 24, 115-120. [CrossRef] [PubMed] 
23. Aziz, T.; Flores-Mir, C. A Systematic Review of the Association between Appliance-Induced Labial Movement of Mandibular Incisors and Gingival Recession. Aust. Orthod. J. 2011, 27, 33-39.

24. Ciavarella, D.; Tepedino, M.; Gallo, C.; Montaruli, G.; Zhurakivska, K.; Coppola, L.; Troiano, G.; Chimenti, C.; Laurenziello, M.; Lo Russo, L. Post-Orthodontic Position of Lower Incisors and Gingival Recession: A Retrospective Study. J. Clin. Exp. Dent. 2017, 9, e1425-e1430. [CrossRef] [PubMed]

25. Yared, K.F.G.; Zenobio, E.G.; Pacheco, W. Periodontal Status of Mandibular Central Incisors after Orthodontic Proclination in Adults. Am. J. Orthod. Dentofacial. Orthop. 2006, 130, e1-e8. [CrossRef]

26. Pernet, F.; Vento, C.; Pandis, N.; Kiliaridis, S. Long-Term Evaluation of Lower Incisors Gingival Recessions after Orthodontic Treatment. Eur. J. Orthod. 2019, 41, 559-564. [CrossRef] [PubMed]

27. Renkema, A.M.; Fudalej, P.S.; Renkema, A.; Kiekens, R.; Katsaros, C. Development of Labial Gingival Recessions in Orthodontically Treated Patients. Am. J. Orthod. Dentofacial. Orthop. 2013, 143, 206-212. [CrossRef]

28. Vasconcelos, G.; Kjellsen, K.; Preus, H.; Vandevska-Radunovic, V.; Hansen, B.F. Prevalence and Severity of Vestibular Recession in Mandibular Incisors after Orthodontic Treatment: A Case-Control Retrospective Study. Angle Orthod. 2012, 82, 42-47. [CrossRef]

29. Thomson, W.M. Orthodontic Treatment Outcomes in the Long Term: Findings from a Longitudinal Study of New Zealanders. Angle Orthod. 2002, 72, 449-455.

30. Gebistorf, M.; Mijuskovic, M.; Pandis, N.; Fudalej, P.S.; Katsaros, C. Gingival Recession in Orthodontic Patients 10 to 15 Years Posttreatment: A Retrospective Cohort Study. Am. J. Orthod. Dentofacial. Orthop. 2018, 153, 645-655. [CrossRef]

31. Morris, J.W.; Campbell, P.M.; Tadlock, L.P.; Boley, J.; Buschang, P.H. Prevalence of Gingival Recession after Orthodontic Tooth Movements. Am. J. Orthod. Dentofacial. Orthop. 2017, 151, 851-859. [CrossRef]

32. Juloski, J.; Glisic, B.; Vandevska-Radunovic, V. Long-Term Influence of Fixed Lingual Retainers on the Development of Gingival Recession: A Retrospective, Longitudinal Cohort Study. Angle Orthod. 2017, 87, 658-664. [CrossRef] [PubMed]

33. Sawan, N.M.; Ghoneima, A.; Stewart, K.; Liu, S. Risk Factors Contributing to Gingival Recession among Patients Undergoing Different Orthodontic Treatment Modalities. Interv. Med. Appl. Sci. 2018, 10, 19-26. [CrossRef] [PubMed]

34. Tepedino, M.; Franchi, L.; Fabbro, O.; Chimenti, C. Post-Orthodontic Lower Incisor Inclination and Gingival Recession-A Systematic Review. Prog Orthod. 2018, 19, 17. [CrossRef] [PubMed]

35. Grassia, V.; Nucci, L.; Marra, P.M.; Isola, G.; Itro, A.; Perillo, L. Long-Term Outcomes of Nonextraction Treatment in a Patient with Severe Mandibular Crowding. Case Rep. Dent. 2020, 2020, 1376472. [CrossRef] [PubMed]

36. Kan, J.Y.K.; Morimoto, T.; Rungcharassaeng, K.; Roe, P.; Smith, D.H. Gingival Biotype Assessment in the Esthetic Zone: Visual versus Direct Measurement. Int. J. Periodontics Restorative Dent. 2010, 30, 237-243.

37. Ainamo, J.; Bay, I. Problems and Proposals for Recording Gingivitis and Plaque. Int. Dent. J. 1975, 25, $229-235$.

38. O'Leary, T.J.; Drake, R.B.; Naylor, J.E. The Plaque Control Record. J. Periodontol. 1972, 43, 38. [CrossRef]

39. Serino, G.; Wennström, J.L.; Lindhe, J.; Eneroth, L. The Prevalence and Distribution of Gingival Recession in Subjects with a High Standard of Oral Hygiene. J. Clin. Periodontol. 1994, 21, 57-63. [CrossRef]

40. Pandis, N.; Vlahopoulos, K.; Madianos, P.; Eliades, T. Long-Term Periodontal Status of Patients with Mandibular Lingual Fixed Retention. Eur. J. Orthod. 2007, 29, 471-476. [CrossRef]

41. Jati, A.S.; Furquim, L.Z.; Consolaro, A. Gingival Recession: Its Causes and Types, and the Importance of Orthodontic Treatment. Dental Press J. Orthod. 2016, 21, 18-29. [CrossRef]

42. d'Apuzzo, F.; Nucci, L.; Delfino, I.; Portaccio, M.; Minervini, G.; Isola, G.; Serino, I.; Camerlingo, C.; Lepore, M. Application of Vibrational Spectroscopies in the Qualitative Analysis of Gingival Crevicular Fluid and Periodontal Ligament during Orthodontic Tooth Movement. J Clin. Med. 2021, 10, 1405. [CrossRef] [PubMed] 